\title{
Editorial
}

\section{Poderes, Leis e Sociedades na Antiguidade Tardia e no Medievo}

\author{
Powers, Laws and Societies in Late Antiquity and Middle Ages
}

\begin{abstract}
Marta de Carvalho Silveira ${ }^{1}$
Rosiane Graça Rigas Martins²

1 Possui Graduação e Licenciatura em História pela Universidade Federal do Rio de Janeiro (1993), Mestrado em História Social pela Universidade Federal do Rio de Janeiro (1996) e Doutorado em História Antiga e Medieval pela Universidade Federal Fluminense (2012). Atualmente é Professora Adjunta da Universidade do Rio de Janeiro, onde atua na área de História Medieval. É professora também da Universidade Estácio de Sá, atuando na graduação presencial e na modalidade EAD no curso de licenciatura e bacharelado em História. E-mail: martadecarvalhosilveira@gmail.com.
\end{abstract}

2 Doutora em História Comparada pela Universidade Federal do Rio de Janeiro (UFRJ). Pesquisadora Associada dos Programas de Estudos Medievais da Universidade Federal do Rio de Janeiro e da Universidade do Estado do Rio de Janeiro (PEM-UFRJ-UERJ). E-mail: rosiane rigas@yahoo.com.br.

Quando propomos esse dossiê intitulado Poderes, Leis e Sociedades na Antiguidade e no Medievo, nosso principal objetivo foi reunir trabalhos que promovessem a interação entre os estudos da Antiguidade e da Idade Média, tendo como fio condutor as relações de poder nos mais diversos níveis que envolvessem a articulação entre as instituições e as instâncias sociais.

Agradecemos, portanto, a todos os pesquisadores que se sentiram estimulados a compartilhar as suas pesquisas e questionamentos com os leitores desse dossiê e que contribuíram para construir pontes reflexivas entre o mundo antigo e o mundo medieval a partir de uma abordagem marcadamente interdisciplinar.

Nesse dossiê foram exploradas temporalidades diversas, documentações diferenciadas, espaços geográficos variados, dinâmicas de poder heterogêneas e amplos caminhos teóricos e metodológicos conduzidos pelos autores de forma a responder às questões primordiais que sustentaram a sua pesquisa.

O ponto de articulação entre os trabalhos selecionados para esse dossiê foi justamente o estudo das relações de poder nos seus mais diversos níveis institucionais, culturais e sociais. Diversas instâncias de poder foram analisadas pelos autores, que as identificaram não só no campo laico, mas também no religioso, bem como se dedicaram a analisar os elementos discursivos que auxiliaram tanto na elaboração das imagens de poder que circularam nas 
sociedades antiga e medieval, mas também dos instrumentos legais que fundamentaram o exercício do poder por parte das instâncias governamentais e eclesiásticas.

Cada um dos autores, dentro do seu recorte de pesquisa, empenhou-se em entender o dinamismo que envolvia as categorias de poder na sua relação com elementos como a hierarquia dos cargos, o controle territorial, o ordenamento social, a construção de símbolos e signos de poder, dentre outros.

Abrindo a discussão em torno da influência que o direito romano exerceu na fundamentação dos aspectos institucionais dos poderes laicos e eclesiásticos na Antiguidade Tardia, Lucas Boamorte, em seu artigo O Direito Romano Tardo-antigo: rupturas e permanências de um elemento constitutivo da Antiguidade Tardia, analisou a elaboração da tradição romanística do direito romano. Tradição essa que considerava o Corpus Iuris Civilis como o seu documento fundador, embora o próprio código já fosse uma ressignificação do direito romano, e influenciou diversas releituras do direito romano no contexto medieval difundindo a noção de que o direito era a herança jurídica legada pelos romanos à civilização ocidental.

Os aspectos que envolvem a elaboração das concepções e das imagens de poder estiveram presentes no artigo de Andréia Taborda, As Virtudes de Constantino versus os Vícios de Maxêncio e Licínio segundo a História Eclesiástica de Eusébio de Cesareia (306-324), que analisou os argumentos utilizados por Eusébio de Cesareia na fundamentação das ações políticomilitares do imperador Constantino, baseando-as na autoridade a ele delegada pelo Deus cristão. Com sua obra, Eusébio contribuiu não só para reforçar a autoridade imperial do próprio Constantino, mas também para lançar as bases discursivas eclesiásticas que fundamentaram os poderes imperiais e monárquicos medievais, e influenciaram a forma como os poderes laicos e os eclesiásticos se relacionaram ao longo da Idade Média.

Avançando pelo campo das reflexões em torno da importância da lei no campo filosófico e da sua fundamentação na autoridade divina, Carlos Thadeu da Costa, em seu artigo A presença da ideia de Lei Eterna nas obras de Dom Álvaro Pais, "Estado e Pranto da Igreja " e de Egídio Romano, "Sobre o poder eclesiástico", comparou o pensamento filosófico de dois importantes autores dos séculos XIII e XIV, Egídio Romano e Álvaro Pais, respectivamente, em busca do impacto sobre eles exercido pelo pensamento tomista. Para tanto, Carlos Costa concentrou a sua análise na formação da noção de lei eterna, aquela responsável por conduzir o mundo e as relações humanas. É sabido que as reflexões conduzidas por Tomás de Aquino, sob forte influência dos textos aristotélicos traduzidos a partir do século XII, influenciaram consideravelmente o pensamento político medieval. 
As fundamentações do poder eclesiástico também estiveram no cerne das discussões propostas por alguns dos autores desse dossiê. No que tange à fundamentação do poder papal, especialmente em seu sentido pastoral, destaca-se o artigo de Rodrigo Vicente, O poder pastoral em Gregório I: um mapeamento teórico. A partir dos estudos teóricos e historiográficos constituídos em torno da construção do poder papal e da análise de elementos presentes na Regula Pastoralis de Gregório, o autor identificou o desenvolvimento de uma concepção de ordem que serviu como parâmetro para o exercício do poder por parte das autoridades eclesiásticas (abades, bispos e diáconos) e laicas (reis e imperadores).

O poder episcopal ganhou protagonismo no artigo de André de Oliveira, intitulado $A$ Vida de São Pelágio da Legenda Aurea e a hierocracia: possibilidades de análise, que analisou as relações de poder desencadeadas nas localidades a partir da liderança episcopal. A inovação do autor reside justamente em utilizar-se de um relato hagiográfico para discutir um tema político. A hierocracia, entendida por Oliveira como "uma das correntes do pensamento medieval que preconiza a primazia do poder espiritual em relação ao temporal", esteve no centro da análise e, assim, a partir do estudo da fonte documental, o autor desvenda os conflitos políticos que envolviam a ordem dominicana e a Igreja Romana na Península Itálica da segunda metade do século XIII, tomando como base a imagem de São Pelágio retratada na Legenda Áurea.

Mergulhando na análise das relações do poder senhorial existente nas sés episcopais castelhano-leonesas, Bruno Álvaro investigou em seu artigo Territórios Senhoriais, Fronteiras Diocesanas: O Poder Senhorial-Episcopal em Castela no Século XII, a documentação diplomática para refletir sobre a forma como tal poder foi exercido pelas altas autoridades eclesiásticas e como envolveram a ocupação, a guarda e a exploração das fronteiras de algumas regiões do reino castelhano-leonês, especialmente Sigüenza, Osma e Tarazona, em meados do século XII. A partir da investigação do seu objeto, Álvaro alerta para a necessidade de se ampliar a discussão em torno do conceito de poder senhorial-episcopal, refletindo sobre a sua operacionalização no estudo das relações que envolvem os poderes senhoriais medievais.

Explorando as relações associativas desenvolvidas entre o poder monárquico e o eclesiástico no contexto ibérico, Láisson Luiz, em seu artigo, D. Dinis e o processo de pacificação com o clero: o estabelecimento das concordatas no reino português, investigou o empenho político do rei Dinis para elaborar um projeto normativo. As concordatas, documentação régia analisada pelo autor, garantiam os direitos de atuação do clero português no que se referia à questões como propriedade, assegurando alguns dos seus privilégios, e marcavam o espaço que ele ocuparia no intenso jogo de poder no qual estavam presentes a nobreza e as estruturas de 
governança. Dessa forma, D. Dinis pretendia pacificar a relação já conturbada entre a monarquia e a igreja portuguesa de forma a não comprometer o seu projeto de centralidade de poder.

Ainda no âmbito da monarquia portuguesa, Maria Fernanda dos Santos, em seu artigo O Favor Divino e a Faculdade de Governar: Sobre D. Afonso Henriques de Portugal (1140-1179), interessada em analisar a forma como a autoridade monárquica afonsina foi elaborada no âmbito da chancelaria régia, debruçou-se sobre a documentação nela produzida e identificou a presença do conceito eclesiológico da Dei Gratia, juntamente ao título de Rex. O uso desses conceitos, para Maria Fernanda Santos mostrou-se eficaz para a fundamentação da autoridade do monarca português não somente a partir da sua atuação político-militar, mas também por estar abalizada pelas virtudes e preceitos cristãos, sendo por Deus instituída.

Mergulhando nos mecanismos legais constituídos pelos monarcas para a extensão do seu poder, que almejava a centralidade, para a sociedade como um todo, Rosiane Martins e Mayara Saldanha, em seu artigo Aspectos Processuais da Legislação Castelhana: as Testemunhas no Fuero Juzgo e no Fuero Real, investigaram o papel jurídico previsto para as testemunhas na instalação e na fundamentação dos pleitos castelhanos, no século XIII. Para tanto, as autoras recorreram ao estudo comparativo dos dois principais códigos jurídicos vigentes no período: o Fuero Juzgo, que o rei Fernando III mandou organizar, e o Fuero Real, composto na corte do seu filho, Afonso X. Após identificar os critérios legais que legitimavam a convocação, a ação e a aceitação das testemunhas, as autoras concluíram que o destaque adquirido pelas testemunhas no pleito encontra-se relacionado ao crescente processo de racionalização dos mecanismos processuais e ao projeto de centralidade de poder defendido inicialmente por Fernando III e continuado por seu sucessor.

Aprofundado a reflexão em torno das conexões existentes entre a formação dos mecanismos legais no âmbito das monarquias ibéricas e o ordenamento social, Andréa da Cunha e James Eduard Sant'anna, em seu artigo A Reconquista Cristã Portuguesa e a Reordenação Muçulmana: o Uso dos Forais como Modelo de Submissão e o Controle Régio nos Séculos XII a $X V$, debruçaram-se sobre o estudo das relações do poder monárquico em Portugal. Tomando como base o estudo das cartas forais, os autores analisaram a forma como se deram as relações de poder entre a coroa portuguesa e as comunidades muçulmanas. Refletindo sobre os mecanismos legais instituídos pela monarquia para controlar e submeter as comunas mouras ou 'mourarias', os autores identificaram que tal esforço de ordenamento encontrava-se intrinsicamente relacionado à demanda pela conquista e a ocupação territorial, considerava vital para a manutenção e a preservação do reino português na Idade Média. 
Avançando nas possíveis interlocuções entre o exercício do poder régio e a regulação da vida feminina, Guilherme Antunes Junior, em seu artigo Yfançonas, burguesas e rústicas: algumas reflexões sobre viuvidade e herança no texto normativo Vidal Mayor de Vidal de Canellas (séc. XIII), analisou as determinações legais propostas acerca das questões patrimoniais que envolviam as mulheres. Usando como fonte de pesquisa um documento jurídico produzido a mando do rei Jaime I de Aragão, o Vidal Mayor, Guilherme Antunes identificou não só algumas das categorias jurídicas femininas nele presentes, mas também os mecanismos legais instituídos pela coroa a fim de intermediar a relação entre essas mulheres, especificamente as viúvas, a sua parentela e o seu patrimônio.

Explorando os mecanismos legais através dos quais o poder monárquico pretendia ordenar o convívio social Thaiana Vieira, em seu artigo Lei suntuária de Valladolid de 1258: a aparência e a moda para as mulheres, os judeus e os mouros, analisou uma legislação suntuária específica da região de Valladolid. A autora concentrou-se em investigar os fatores políticos, socioeconômicos e culturais que levaram a coroa a criar padrões específicos de vestimenta para grupos minoritários, especificamente as mulheres, os judeus e os mouros, e nos informa que a motivação régia encontrava-se relacionada, sobretudo, ao desejo de criar um código de aparências que permitisse a rápida identificação dos sujeitos em uma comunidade marcadamente heterogênea na sua formação social.

Contribuindo para ampliar a discussão em torno da fundamentação do poder régio e a sua relação com o corpo social, Marta Silveira e Cleiton Batista, em seu artigo O poder monárquico e a saúde do corpo feminino na Castela do século XIII, analisaram elementos de um tratado geológico traduzido na corte de Afonso $X$, e que ficou conhecido como Lapidário de Afonso $X$, além de fragmentos das Sete Partidas e do Fuero Real, com o objetivo de identificar as motivações que levaram a monarquia castelhana a zelar pelo bem estar físico das mulheres. Os autores se concentraram no estudo dos cuidados médicos previstos para os males relativos à menstruação e à amamentação e identificaram que grande parte da motivação monárquica para assegurar a saúde feminina estava relacionada à necessidade de manutenção e de reprodução do corpo social, do qual o rei era o cabeça, sendo responsável também pelo seu ordenamento.

Concentrando-se no entendimento das relações de poder no espaço citadino, Thatiane de Melo, em seu artigo Um breve panorama sobre a Península Itálica na Baixa Idade Média, a partir do caso específico da cidade de Florença, explicitou, através de um quadro contextual geral, os conflitos políticos que envolveram o Papado, o Sacro Império Romano Germânico e os 
poderes locais florentinos e a forma como eles influenciaram diretamente na dinâmica de crescimento da cidade de Florença, tornando-a uma referência política e cultural, sobretudo no cenário mediterrânico.

Como mencionamos no início da apresentação desse dossiê, as relações de poder foram entendidas por seus autores de forma ampla e interdisciplinar, logo, não poderíamos deixar de abrigar aqui estudos que se propuseram a estreitara o entendimento das questões históricas a partir do diálogo com o campo da linguagem e da literatura, onde considera-se que na construção da linguagem, em seus mais diversos níveis, estão presentes relações de poder que se expandem por toda a sociedade.

Nesse sentido, Fernando Oliveira Junior, em seu artigo Escrita Pedagógica e Poder: Feiticeiras, Mediadoras e Literatura Vicentina, analisou o potencial pedagógico que a obra do dramaturgo português Gil Vicente alcançou na elaboração de um discurso moralizante direcionado ao público feminino, construindo topois femininos como os das feiticeiras e das mediadoras. Topois esses que, além da função de entretenimento do público, garantiam a reprodução dos valores morais considerados adequados às mulheres, que poderiam ver-se estimuladas, através das peripécias das personagens, tanto a inspirar-se nos seus exemplos para aprender com elas os padrões comportamentais considerados adequados quanto para criticar àquelas mulheres que exibissem comportamentos desviantes.

Ainda explorando as pontes sempre profícuas entre a literatura e a história, Lunielle Bueno, em seu artigo Entre Florestas, Loucuras e Profecias: os Merlins medievais, suas adaptações e ressignificações, analisou a construção literária da figura do mago Merlin nas obras de Godofredo de Monmouth (século XII) e de Roberto de Boron (século XIII) e a identificou como um instrumento utilizado pelos respectivos autores para veicular as suas críticas ao momento político em que viviam. Cada um em seu contexto, os autores elaboraram em suas obras a figura do mago como alguém tem noção de como se deve governar e em quem os governantes devem se inspirar para melhor conduzir o seu reino. Tal imagem do mago, conforme observou Bueno, não se extinguiu na Idade Média, mas continuou a inspirar produções culturais posteriores, perpetuando, assim, um imaginário simbólico em torno desse personagem literário.

Caminhando para o entendimento da dinâmica que envolve a produção de um texto e as condições históricas e intelectuais em que se insere o seu autor, Everton Grein e Gabrielly Geisler, no artigo intitulado O De Orthographia de Alcuíno de York: Estudo de um Manual do Século VIII, situaram Alcuíno de York em seu contexto e mapearam os fatores que o motivaram a redigir, no século VIII, um pequeno manual de latim. O empenho de Alcuíno por padronizar o 
uso e a forma do latim escrito, segundo os autores, explica-se pelo significativo papel por ele desempenhado no renascimento carolíngio, na medida em que a padronização do latim em muito favoreceu a configuração dos mecanismos de governança do poder carolíngio.

Coroando os esforços desse dossiê para aprofundar as pontes analíticas entre temáticas antigas e medievais e valorizar o diálogo interdisciplinar, fechando o dossiê, temos o prazer de apresentar a tradução de duas obras extremamente significativas para o entendimento do período medieval.

Continuando o seu projeto de tradução da obra De ira Dei de Lactâncio, escritor tardoantigo pouco conhecido em língua portuguesa, o professor Cristóvão José dos Santos Júnior abrilhantou significativamente esse dossiê publicando os capítulos XV, XVI e XVII da referida obra. Firmiano Lactâncio, que teria vivido entre os séculos III e IV, foi reconhecido em seu contexto por sua vasta cultura intelectual, a ponto de tornar-se preceptor Crispo, filho do imperador Constantino. De acordo com Santos Júnior, sua obra reverberou e influenciou os princípios filosóficos e teológicos patrísticos, contudo ela ainda não foi totalmente traduzida para a língua portuguesa. A tradução aqui apresentada, portanto, pretende tornar Lactâncio conhecido do público e estimular novas reflexões acerca dos seus escritos.

Também contribuindo para trazer ao público e aos pesquisadores novas fontes documentais a serem investigadas, os professores Alexander de Carvalho e Carolina Fortes traduziram pela primeira vez para a língua vernácula, as Constituições, texto de vital importância para o estudo da história do ramo feminino da Ordem dos Frades Pregadores. As Constituições trazem os princípios normativos que regulavam as dinâmicas internas de convívio das irmãs da Ordem. Fundamentadas na concepção de religiosidade e no arcabouço simbólico que baseava a visão de mundo dos componentes da Ordem, a análise dessa documentação poderá contribuir muito para aqueles que se interessam, dentre outros aspectos, pelo estudo das instituições religiosas medievais e das relações de gênero.

Traçado um breve panorama dos artigos disponíveis nesse dossiê esperamos que seus leitores sejam estimulados a tomar essas pesquisas como pontos de partida para o aprofundamento dos seus próprios estudos e que estreitem, ainda mais, as pontes reflexivas entre antiquistas e medievalistas, investindo-se em uma perspectiva interdisciplinar na elaboração da análise histórica. Nesse espírito, entregamos aos leitores esse dossiê. 